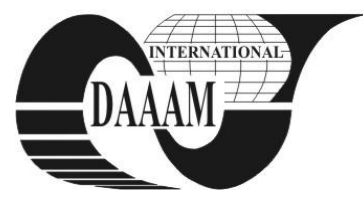

Annals of DAAAM for 2011 \& Proceedings of the 22nd International DAAAM Symposium, Volume 22, No. 1, ISSN 1726-9679 ISBN 978-3-901509-83-4, Editor B. Katalinic, Published by DAAAM International, Vienna, Austria, EU, 2011 Make Harmony between Technology and Nature, and Your Mind will Fly Free as a Bird Annals \& Proceedings of DAAAM International 2011

\title{
THE QUANTUM OF MIND: PHYSICS AS COMPLEMENTARY COGNITIVE SEMANTICS KNOWLEDGE
}

\author{
MACHOVA, S[vetlana]; KRATOCHVIL, P[etr] \& KLECKOVA, J[ana]
}

\begin{abstract}
In this article we are examining and comparing semantic knowledge from cognitive linguistics, philosophy, depth psychology and quantum physics and attempts to create a probabilistic picture of our mental life and interaction. New paradigms in computational linguistics are reflected by research methods using Free Association Experiment (FAE) based on cognitive metaphor stimuli. It is the first NLP tool of its kind, providing a fundamentally new source of empirical data examining hidden dimension of the human mind. Our research methodology included constructing a database of metaphorical stimuli, randomly presenting these to respondents, and tabulating FAE responses both by participant and by stimulus, analyzed by frequency of semantic type. The results presented as a semantic network gave us a unique opportunity to discover the probabilistic nature of mind revealing itself in metaphors as a kind of electromagnetic field. Key words: Semantics, Associations, Quantum, Mind.
\end{abstract}

\section{INTRODUCTION}

The concept represents the cognitive dimension of mind based on the psychoanalytic methodology of Free Association Test. In the research we conducted Free Association Experiment (FAE), giving us access not only to the diagnosis of psychopathological conditions, but also to the information about the primary ways of thinking, totality of mind experience acquired by all humankind,- to collective unconscious data.

The Elegant Mind Project (EMP) is knowledge representation research that uses Free Associations Test data to create a semantic network of Inner Self (Mind) from associations to a unique list of cognitive metaphor stimuli. EMP is a fundamentally new resource of deep semantic knowledge, a platform for mind study and optimizing the human communication process with electronic resource. Two main methodologies are combined in this project: Free Association Test (C.G. Jung) and Cognitive Metaphor Theory of Inner Self (Lakoff \& Johnson, 1999).

According to K. Ahrens (2005) huge interest in embodied cognition has increased the need for cognitive models reflecting the relationship of the Inner Self within and out of the physical world. As W. James noticed we are divided into ,spiritual me, social me and material me". Conceptual Metaphor Theory rejects the notion that metaphor is a decorative device. Metaphor structure thinking and knowledge. (Deignan, 2005:13). Conceptual metaphor such as HAPPY IS UP , UNHAPPY IS DOWN, occurs when linguistic metaphor "realizes" the concept itself in expressions like "I am feeling up", "That boosted my spirits" and "Feeling on the top of the world"(Deignan, 2005:14) "linguistic metaphors are highly frequent, which suggests that they are indeed evidence for underlying mental structures". (Deignan, 2005:15) The fact that the most people do not even see the metaphor in expressions such as "I,m feeling up" argued that "this very unmarkedness should be taken as a proof of the importance of metaphor" ( Deignan, 2005:15). They form background of our abstract thinking. The other conceptual metaphor for emotion
HAPPINESS IS LIGHT (Kovecses, 1991 in Deignan, 2005) like "To shine with happiness", "His face became dark when he realize that", "Let shining your truth colors", "Her personality is shining through" supports the idea of inner life as something which is "enlightened" by personality (Inner Self) and colored by emotions. The other important concept is a CONTAINER metaphor ((Lakoff \& Johnson, 1980, 1999) such as "I was beside myself with anger", I am not myself today" , "I have got you under my skin", "I always accepted (let in) him as a person". The research confirmed dualistic theory about mind possessing, leaving or transcending the body.

\section{METHODS}

To create an association semantic network we used a set of web application tools. An database was generated in SQL by an original algorithm in on-line mode. In contrast with already existing WordNets based on existing corpuses processing, these algorithms work on immediate authentic respondent answers for given text stimuli (Machova at al., 2010).

First, we created a list of 400 stimuli for Free association Test in Czech language. The stimuli appeared to each respondent in a random order, and she/he had the opportunity to write $0-3$ responses in Czech to each stimulus. This application is used for writing associations to stimuli which is being offered, where respondents has to write first word or phrase which immediately came up into their mind.

Basic statistics were provided online. The administrator can display either responses categorized according to respondents or the issues, where individual responses are sorted according to the frequency of their occurrence for each stimulus. This application can be used not only for psychological, medical and sociological research but also as a multilingual dataset, where the user only selects stimuli in the preferred language.

\section{EXPERIMENTAL FINDINGS}

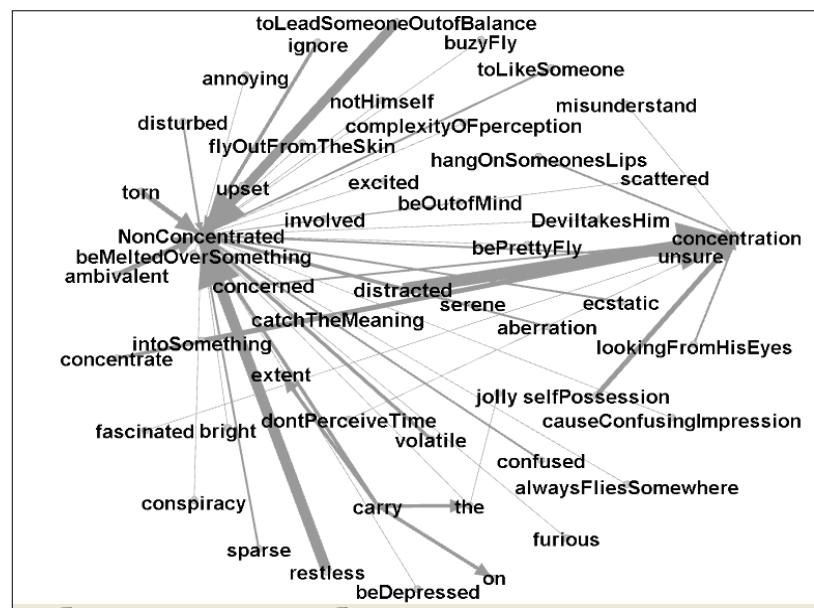

Fig. 1. Concentrated/distracted state of Mind. The semantic network 
In the database we have collected 12,673 word responses for 400 stimuli from almost 200 participants. Primarily we were interested in creating semantic network from obtained data. The example part of this network we can see from the Fig 1 above We also examined which stimuli-response pairs occur more frequently, which responses occurred more often, are there any unexpected connections between certain words, which answer occurred more often, which stimuli are semantically clustered by the same answer, which stimuli are occurred as an answer and in what context?

We have classified our data from different points of view; we were after all interested in the qualitative findings. Unique associations produce another cognitive metaphor in connection with these stimuli. Most of the participants were university students mostly in humanities field such as history or philosophy.

The linguistics data collected by this means were intrinsically different from what we have know about the mind from the neuroscience which helped us to imagine the cognitive function of the human mind as an access to collective unconsciousness. Despite the relatively greater variation of the individual responses, there is obvious pattern of the synchronicity.

Analyzed data were lemmatized by an SQL and MS Excel and classified into 75 primary semantic dimensions and cases were grouped using Microsoft ACCESS. The most common answer contained lexeme mimo (literally- to be out of body) which belongs to CONTAINER conceptual metaphor and were correlated with distracted state of Mind.

Strikingly, as a response, "out of body" has occurred 151 times. As we see on the Fig. 2 below stimuli 32 and 33, 30 and 31,26 and 27 are grouped in the pairs together . It seems that to become con-fused (lit. fused with something else) we first need to be puzzled, that to be taken could means - to be taken out of reality and someone who completely blown can be at the same time mixed (Czech zamotán ) lit. bended in a communication network.

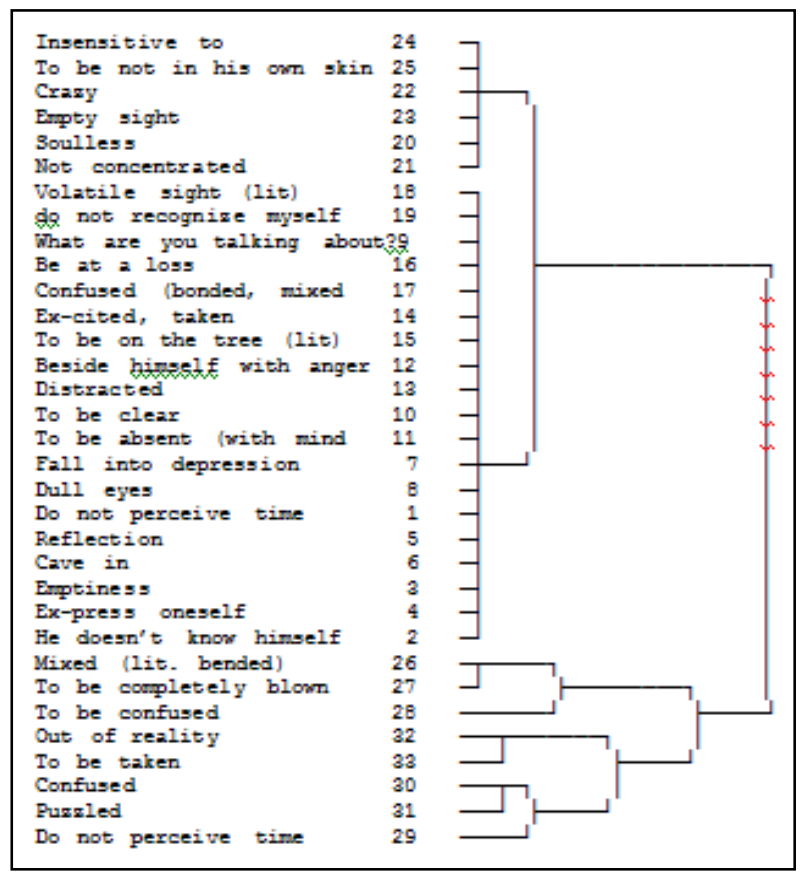

Fig. 2. Clustering the stimuli related to the "out of body" concept

Experimental findings report that most frequent agreement in associations among participants was for the such stimuli as: distress $60 \%$ of participants responding to this stimuli, to disappear (evaporate) $63 \%$, concentrate $65 \%$, existence $75 \%$, introversion $83 \%$.
These associations seem to represent conceptual metaphors of CONTEINER (Lakoff \& Johnson, 1999) being out of body, self is a light, fluid, gas, life is a spinning. See examples below with English translation.

\section{FUTURE RESEARCH}

The Elegant Mind project presented in this paper is supported by the Czech Science Foundation grant 106/09/0740. The concept represents the cognitive dimension of mind based on the psychoanalytic methodology of Free Association Test. In the research we conducted Free Association Experiment (FAE), giving us access not only to the diagnosis of psychopathological conditions, but also to the information about the primary ways of thinking, totality of mind experience acquired by all humankind,- to collective unconscious data.

The uniqueness of this pilot concept is an idea to draw a picture of the universal language semantic network of Essential Self and its interaction. New paradigms in computational linguistics are reflected by new research methods using Free Association Experiment. As a limitation of the research we could mention a subjectivity of qualitative approach used in the process of lemmatization of the obtained data. It is the first of its kind of NLP tool, providing a fundamentally new source of language research. (Machova at al., 2010) Future research plans are: within the processing of associative data we aim to build a 3D Semantic network, which creates the model of Mind and its interaction. We plan to extend the network by data obtained in Russian and English.

\section{CONCLUSION}

Empirical findings about the phenomenology of mind gained from Associative Experiment, has opened a new dimension of artificial intelligence research, allowing us to create a link between a collective unconscious level and a conscious Mind. Essential Self metaphors described by the association experiment allow us to identify the main structures of a priori semantic web hidden beyond the language. Our claim is that literal meaning of the cognitive metaphor is not necessarily arbitrary and metaphorical itself as we were used to think. Their literal meaning is a huge field of research discovering hidden structures of a mind. Literal meaning and literal translation of cognitive metaphors of mind, which doesn't usually make common sense in the visible dimension is a universal phenomena occurred throughout all languages as we have noticed that it is often metonymies which needs to be uncovered in its full length. Thus associations and other languages equivalent can help us to do it.

\section{REFERENCES}

Deignan, A.(2005), Metaphor and Corpus Linguistics,. ISBN 902723892 8, University of Leeds

Lakoff, G. \& Johnson, M. (1980). Metaphor We Live By, ISBN0-226-46304-1 University of Chicago Press,

Lakoff, G. (1996). Sorry, I'm not Myself Today: The Metaphor System for Conceptualizing the Self, Edited by Gilles Fauconnier and Eve Sweetser, Spaces, Worlds, and Grammar: ISBN: 9780226239231 University of Chicago Press

Lakoff, G. \& Johnson, M. (1999). Philosophy in the Flesh. The Embodied Mind and Its Challenge to Western Thought. ISBN 0-465-05674-1, N.Y.: Perseus Books

Machová S, Kratochvil, P, Klečková J (2010). The Elegant Mind. A New Insight To The Deep Semantic Network, Annals of DAAAM for 2010 \& Proceedings of the 21st International DAAAM Symposium "Intelligent Manufacturing \& Automation: Focus on Interdisciplinary Solutions", ISSN 1726-9679, Zadar, 2010 